\title{
Banner Plans to Issue New Bonds to Cover University of Arizona Medical Center Purchase
}

Modern Healthcare is reporting that Banner Health is issuing new bonds this week to refinance older debt (1). Banner financed the $\$ 1$ billion purchase of the University of Arizona Health Network (UAHN) including the University of Arizona Medical Center with a $\$ 700$ million short-term loan from investment bank Mizuho in February. Banner is issuing \$100 million in tax-exempt, fixed rate Series 2015A bonds. It is also planning to take on an additional $\$ 500$ million in taxable and tax-exempt debt that will be used to replace the short-term loans associated with the purchase.

Banner is focusing on how to improve the return on its UAHN investment, which has dragged down its earnings. UAHN's financial performance has deteriorated with an operating margin declining to $-4.3 \%$ in fiscal 2014 , down from $-1.2 \%$ the previous fiscal year. Before that, UAHN was profitable, according to Banner Chief Financial Officer Dennis Dahlen. Banner reported an operating surplus of \$107.6 million on \$3.4 billion in revenue for the first half of this year (2). In the prior-year period, its operating surplus was $\$ 186$ million on $\$ 2.7$ billion in revenue.

In an attempt to increase profitability, Banner has implemented a leadership incentive plan at UAHN and labor productivity tools. The executive compensation firm Sullivan Cotter has also been hired to design a new physician practice compensation structure. Dahlen noted that Banner believes that it will stabilize UAHN's finances by the end of next year, with profitability returning in 2017.

With the purchase of UAHN and the much smaller 44-bed Payson Regional Medical Center in July, Banner now reaches $82 \%$ of Arizona residents and is by far Arizona's largest health care system. Banner also plans to expand UAHN's health plans statewide to capture additional market share. The impact the debt from Banner's drive for market share will have on health care prices and Banner employees is unclear.

Richard A. Robbins, MD

Editor

Southwest Journal of Pulmonary and Critical Care

\section{Reference}

1. Kutscher B. Banner prepares to issue new debt amid UAHN turnaround efforts. Modern Healthcare. October 20, 2015. Available at: http://www.modernhealthcare.com/article/20151020/NEWS/151019914?utm source =modernhealthcare\&utm medium=email\&utm content=20151020-NEWS151019914\&utm campaign=am (accessed 10/21/15).

2. Kutscher B. Banner aims to cut costs from UAHN as earnings lag. Modern Healthcare. August 25, 2015. Available at: http://www.modernhealthcare.com/article/20150825/NEWS/150829923 (accessed 10/21/15). 